This paper suggests a method to search for an incoming object in order to identify its unambiguously, based on the integration of information spaces into intermediate unified information space. At the same time, the incoming object identification process involves appropriate attributes.

This paper describes the process of information object arrangement within a unified information space that forms for a set of dynamically changing objects. It should be noted that each subject in the set collects information about the environment, including interaction with other objects. In the process of forming a unified information space, the information system collects information from data sources that are represented in different formats. The system then converts this information and forms a unified information space, thereby providing users with information about objects.

A two-tier system of connections at the global (cloud) and local (fog) levels of interactions has been considered. At the same time, it should be noted that a unified information space formation requires the implementation of tools to support the transformation of information objects; that necessitates the implementation of translators - special converters at different levels.

$A$ method to combine information spaces into an intermediate unified information space has been proposed; analysis was performed to determine the time and efficiency of the search for incoming objects within it.

It was experimentally established that the more parameters that describe an information object, the less the time to identify an object depends on the length of the interval.

It has also been experimentally shown that the efficiency of finding incoming objects tends to be a directly proportional dependence while reducing the length of the interval and increasing the number of parameters, and vice versa

Keywords: unified information space, object identification, parameter of the incoming object, information object, search method
UDC 004.021

DOI: $10.15587 / 1729-4061.2021 .229568$

\title{
DEVISING A METHOD TO IDENTIFY AN INCOMING OBJECT BASED ON THE COMBINATION OF UNIFIED INFORMATION SPACES
}

Vadym Mukhin

Doctor of Technical Sciences, Professor

Department of Mathematical Methods of System Analysis*

Valerii Zavgorodnii

Corresponding author

$\mathrm{PhD}$, Associate Professor**

E-mail: zavgorodniivalerii@gmail.com

Yaros Iav Kornaga

Doctor of Technical Sciences, Associate Professor

Department of Technical Cybernetics*

An a Zavgorodny a

PhD, Associate Professor**

levgen Krylov

$\mathrm{PhD}$, Associate Professor

Department of Technical Cybernetics*

Andri i R y alochka

$\mathrm{PhD}$, Senior Researcher, Head of Laboratory Laboratory "Center of Testing and Diagnostics of Semiconductor Sources of Light and Illumination Systems"***

Vasyl Kornaga

$\mathrm{PhD}$, Senior Researcher

Department of Optoelectronics***

Rom a n B elous

Postgraduate Student

Department of Technical Cybernetics* **Department of Information Technologies and Design State University of Infrastructure and Technologies

Kyrylivska str., 9, Kyiv, Ukraine, 04071

*National Technical University of

Ukraine «lgor Sikorsky Kyiv Polytechnic Institute»

Peremohy ave., 37, Kyiv, Ukraine, 03056

***V.E. Lashkaryov Institute of Semiconductor Physics NAS of Ukraine Nauky ave., 45, Kyiv, Ukraine, 02000
Received date: 22.03 .2021 Accepted date: 25.05 .2021 Published date: 29.06 .2021
How to Cite: Mukhin, V., Zavgorodnii, V., Kornaga, Y., Zavgorodnya, A., Krylov, I., Rybalochka, A., Kornaga, V., Belous, R. (2021). Devising a method to identify an incoming object based on the combination of unified information spaces. Eastern-European Journal of Enterprise Technologies, 3 (2 (111)), 35-44 doi: https://doi.org/10.15587/1729-4061.2021.229568

\section{Introduction}

Identifying an incoming object in a unified information space requires an informed choice of the most appropriate methods for doing so $[1,2]$. It should be taken into consideration that this choice of object identification method should involve the possibility of taking into consideration a series of uncertainties [3, 4], such as the absence for some reasons of some of the attributes of an incoming object $[5,6]$.

A unified information space is an information model of a complex subject area that includes information objects, connections between them, the environment of the space itself, as well as the processes that accompany its creation [7-9]. In the process of its formation, the information system [10-12] 
underlying the creation of a unified information space performs the following $[2,13,14]$ :

- collects information from data sources that are represented in different formats;

- converts object-specific information;

- forms a unified information space;

- provides users with information about objects.

There are known procedures for integrating automation systems with a unified information space [15-17] and semantic search [18-21]. The methods that identify an incoming object within the unified information space are much in demand, which is confirmed by works [22-24]. However, the solutions obtained using these methods allow the identification of an incoming object provided that only one unified information space is used [1,25]. This shows the relevance of research into the identification of incoming objects in information spaces.

\section{Literature review and problem statement}

Study [26] analyzes the relationship between the concepts of the information space, the information field, and the information environment, which make up a hierarchical series of concepts and are not equivalent. The authors demonstrated the following:

1) information space and information field are divided into natural and artificial;

2) the information field is built into the information space;

3) the information environment is a subset of the information space and information field;

4) the information environment is always associated with a particular object. At the same time, the passivity of the information space and the activity of the information field are noted.

A description of modern technologies for representing and integrating disparate data can be found in work [27]. The method described for integrating heterogeneous spatial data is based on the concept of metadata in modern automated information support and interaction systems. The use of this method bypasses the shortcomings mentioned in the cited work but, despite its advantages, the issue related to the organization of tools to support the conversion of information objects remains to be studied.

Paper [28] reports a comprehensive procedure that improves the speed of processing of different types of data in intelligent systems. The proposed methodology improves the efficiency of intelligent decision-making support systems through the integrated processing of data that circulate in them. The downside of that procedure is the need to process large amounts of data to determine the state of the monitoring object.

To find hidden objects, work [29] suggested a method based on the classification of objects. However, the choice of the most informative momentary attributes of classification involved the metric criterion of informativeness.

Work [30] takes into consideration the specificity of the unified information space architecture in order to connect existing data sources that are needed for sharing in the management of complex manufacturing processes. As part of the design of the system architecture, a service-oriented approach is proposed, which is to divide the system into components (services). This approach describes a role-based data access model that is the basis for determining security policy.
To create a unified information space, many businesses use cloud storage facilities that allow large amounts of data to be used for free. In turn, such a unified information space should have sufficient functionality that could make it possible to work with data in a single format. Developing views on data formalization can be found in work [31], which describes the system model of integrating content from cloud storage into a single enterprise information space, as well as the results of its implementation. Although the solution can be used in the context of training projects for a unified information space, the proposed model is only conceptual and has no practical confirmation.

Paper [32] examined the identification of an information object based on a step-by-step analysis of features within a unified information space, which allowed the authors to unequivocally identify the input information object on the relevant features.

The systematization of the results from the cited studies allows us to argue that the approaches and methods discussed above to solve the task of identification of an incoming object are based on the formalization and analysis of its features, as well as the subsequent search for an incoming object in a unified information space at the local level.

The approaches described in [26 32] make it possible to identify an incoming object only locally. It follows that trying to identify the same object by other local information space would not produce the same result. To improve the efficiency of identification of an incoming object, both locally and globally, it is proposed to use a set of information spaces, united in an intermediate unified information space. Then, within this space, it is proposed to carry out the process of identification of an incoming object based on the appropriate attributes.

\section{The aim and objectives of the study}

The aim of this work is to devise a method for combining information spaces into an intermediate unified information space for the unambiguous identification of an incoming object.

To accomplish the aim, the following tasks have been set:

- to design a mechanism for the formation of a unified information space provided there are separate information spaces based on their unification;

- to analyze the efficiency and time of finding incoming objects in information spaces based on the proposed method.

\section{The study materials and methods}

The process of placing information objects in unified information space is as follows: the initiating subject, as the operations take place, transmits the primary information about the information object to the subject-integrator of a unified information space through the communication network. Information objects of a unified information space are processed by integrators to perform their functions in the area of their responsibility. Subjects-integrators, having received primary information from the subjects-initiators, generalize, integrate information objects of a unified information space. Some of the information is entered into a single information base for use by all actors, and the remainder of the information is used only by certain actors who have appropriate access to it. Integrated objects are used by each local entity to obtain information about the subject area in a unified information space. 
A unified information space is formed for a set of dynamically changing objects. Each subject of the set collects information about the environment, including interactions with other objects.

The two-tiered communication system in the following set is considered: at the cloud level - global interaction, and at the fog level - local interaction. In this case, to form a unified information space, one needs to implement tools to support the transformation of information objects. In this case, these tools are implemented separately at the fog level (local level) and separately at the cloud level (global level). To support a unified information space, it is necessary to unite all individual information objects; this requires the implementation of special converters - translators at different levels.

In a general case, local-level transformation tools may also differ, in which case the converter would lead the concept of a unified information space to a single format at the global level. The tools of transformation at the global and local levels can change as a unified information space operates. In this case, adaptive and two-way converters would be required. The global, local levels, and converters in a unified information space are shown in Fig. 1.

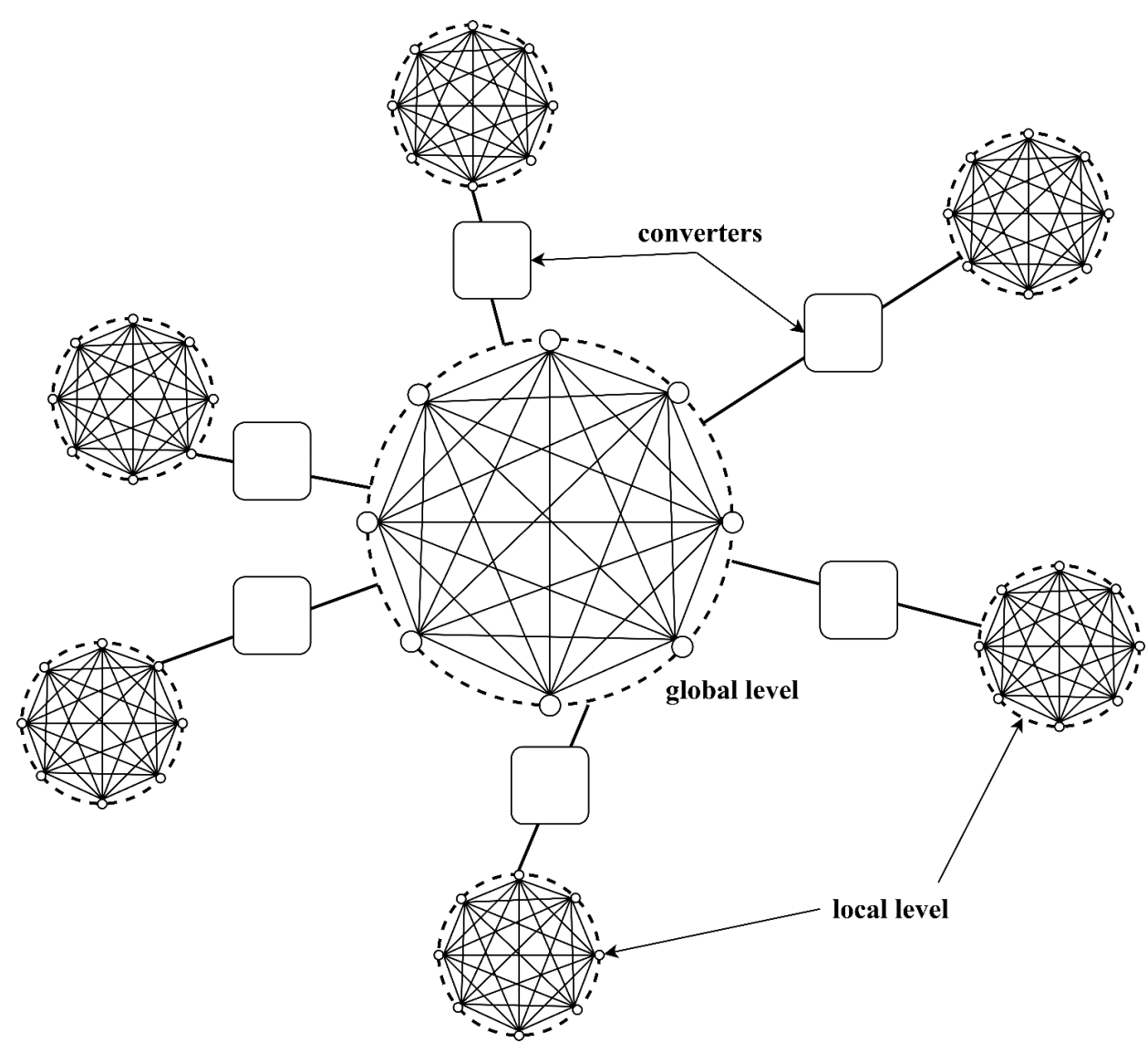

Fig. 1. Global, local levels and converters in a unified information space mation space

capture identifiable systems, monitor data information, and assess the informativeness of data on prevalence indicators.

\section{Results of studying a method of identifying an incoming object based on the combination of information spaces}

\subsection{Designing a mechanism to form a unified infor-}

Underlying the mechanism being designed is the process of combining individual information spaces into unified information space. In this case, all information objects (IOs) from all information spaces $(I S)$ are combined into one intermediate unified information space $\left(U I S_{i n t}\right)$ for further search of an incoming object $(O)$ within it. The structure of the unification of information spaces into an intermediate unified information space is shown in Fig. 2.

The method of identifying an incoming object by combining information spaces into an intermediate unified information space consists of the following steps:

- Step 1. Information spaces are formed.

- Step 2. From each information space, all information objects are combined into one intermediate unified information space.

- Step 3. In the intermediate unified information space, there is a process of exclusion of repetitive information objects, that is, the intermediate unified information space itself is being rebuilt.

- Step 4. There is a process of comparing the information objects of the intermediate unified information space with a certain incoming object $O_{i}$, which has a set of parameters $\left(P_{1}, P_{2}, \ldots, P_{n}\right)$. If the value of each parameter of this object falls into the valid value interval for the corresponding feature of any information object from the intermediate unified information space $\left(M-D \leq P_{i} \leq M+D\right)$, then the incoming object is clearly identified. In other words, $O_{i}=U I S_{i n t}\left(I O_{k}\right)$.

- Step 5. The missing features of the incoming object are being clarified. If there are not enough attributes, the sensors

Such a scheme makes it possible to maintain the survivability of a unified information space. If one or more objects forming a unified information space fail, the missing information can be obtained from a global level. If objects that support the global level (cloud) fail, the missing information can be restored by converting and integrating indicators from local levels.

In addition, to support survivability under the conditions of data scarcity, identifiable systems are used to re-read these parameters. And if, after that, the parameter was not counted by sensors, it remains unaccounted for - NULL.

- Step 6. The derivation of the found object, the group of objects, or the fact that the object being analyzed is new; such an object is then placed in a unified information space with the smallest number of information objects.

Let us consider the peculiarities in deriving a formula of the search for an information object based on theoretic-multiple formalism. 


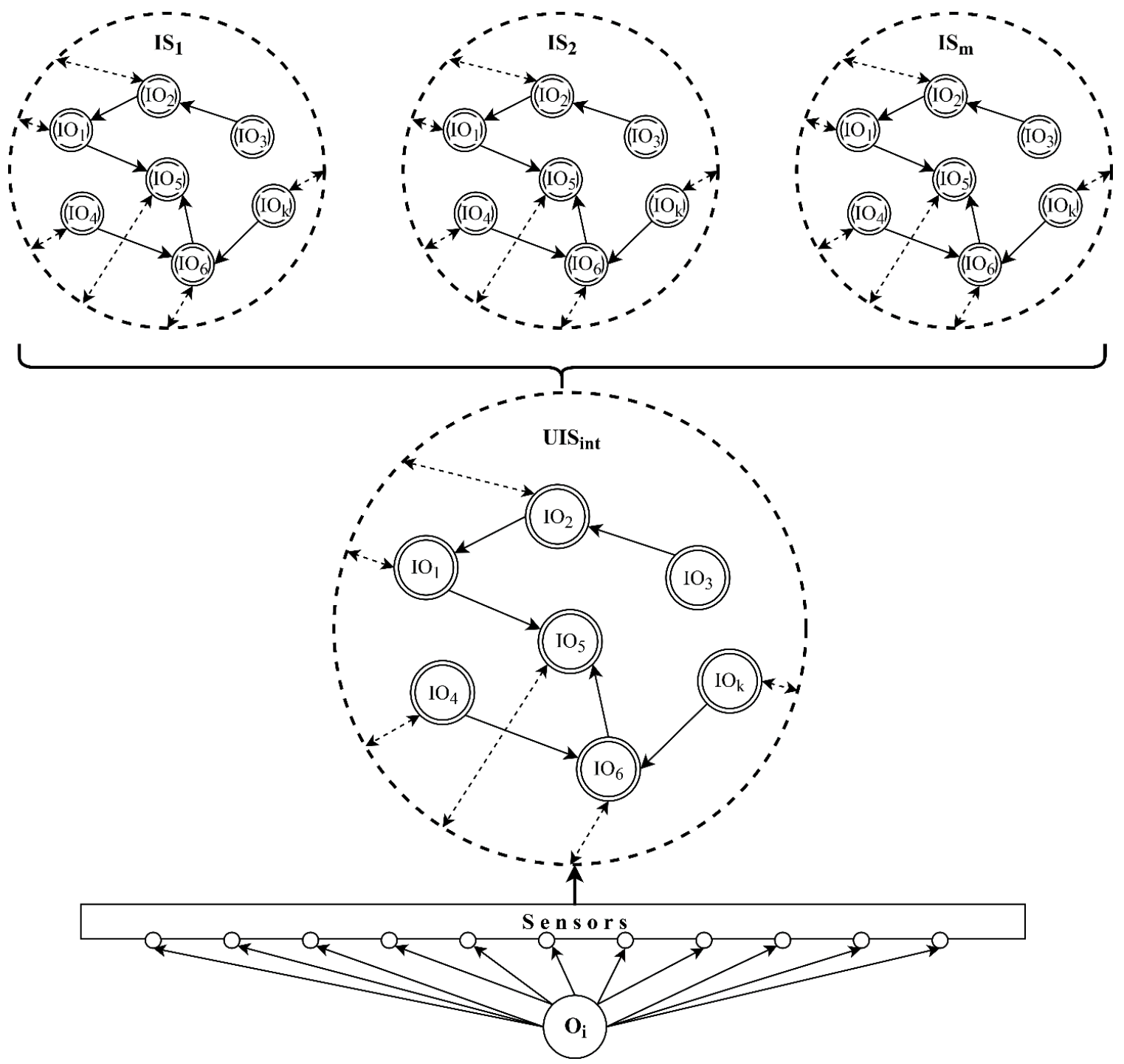

Fig. 2. Combining information spaces into an intermediate unified information space

Let us denote a set of information objects by expression (1):

$$
I S=\left\{i o_{i} \mid i=1, \ldots, k\right\},
$$

where $i o_{i}$ is an information object.

In this case, the set of attributes on $I S$ can be represented by expression (2):

$$
P(I S)=\left\{P_{j}(I S) \mid j=1, \ldots, l\right\},
$$

where $l$ is the number of acceptable attributes.

In expression (3), the possible values of the attribute $P_{j}$ are described:

$$
p^{P_{j}}=\left\{p_{j 1}, \ldots, p_{j m_{j}}\right\}
$$

where $m$ is the number of valid values for the attribute $P_{j}$.

If at least the only $P_{j}$ attribute value is assigned to the object $i o_{i}$, then the set of the assigned attribute $P_{j}$ values for the object $i o_{i}$ is described by expression (4):

$$
p_{j}\left(i o_{i}\right)=\left\{p_{j s}\left(i o_{i}\right), s \in\left\{1, \ldots, m_{j}\right\}\right\} \subset p^{P_{j}} .
$$

In the case the $P_{j}$ attribute values for the object $i o_{i}$ are not assigned (that is, the attribute is equal to an empty set $\left.p\left(i o_{i}\right)=\varnothing\right)$, then the set of all attributes' values for the object $i o_{i}$ is described by expression (5):

$$
p_{j}\left(i o_{i}\right)=\left\{p_{j}\left(i o_{i}\right) \forall j: j \in\{1, \ldots, l\}\right\}, \quad p_{j}\left(i o_{i}\right) \neq \varnothing .
$$

Then, the search for the object $i o_{i}$ based on its attributes is represented as a set of objects of the type $\left\{\right.$ attribute $P_{j}$ : a value of the attribute $P_{j}$ fo the object $\left.i o_{i}\right]$.

Therefore, the search formula based on the attributes $F P\left(i o_{i}\right)$ of the object $i o_{i}$ can be represented as (6):

$$
F P\left(i o_{i}\right)=\left\{\begin{array}{l}
{\left[P_{j}: p_{j}\left(i o_{i}\right)\right] \mid P_{j} \in P(I S), p_{j}\left(i o_{i}\right) \in p^{P_{j}} \forall j:} \\
j \in\{1, \ldots, l\}, p_{j}\left(i o_{i}\right) \neq \varnothing
\end{array}\right\} .
$$

To generate a query to obtain the desired sample of the information objects $U I S_{\text {int }} \subset I S$, one sets step by step in the process the values for a subset of attributes in order to build a search formula based on attributes. 
5.2. Analysis of the effectiveness and time of finding incoming objects in information spaces

We have analyzed the effectiveness of searching for incoming objects in information spaces by combining information spaces into intermediate unified information space.

Five information spaces out of 20,000 information objects each were constructed for the experiments.

The percentage of missing parameters in the information objects (NONE) was $6 \%$.

The series were performed, 100 experiments each, with certain probabilities $(5,10,15,20$, and $25 \%$, respectively) that the parameter is not read by sensors (NULL).

The programming environment for the implementation of experiments. The affordable and distributed software tools that we propose to use in the implementation of the method of combining information spaces into a single intermediate information space include the following components:

- the method is implemented in the Microsoft Windows 10 operating system environment;

- microsoft's SQL Server 2017 serves as a database management system;

- microsoft Visual Studio 2019.Net Core is used as a development environment;

- the software makes it possible to conduct experiments by assigning characteristics and visualization using Windows Presentation Foundation.

Experiment 1. Consider the case where each of the 20,000 information objects is described by 7 parameters in each of the 5 information spaces. Table 1 gives a fragment of 10 information objects of the first information space $\left(I S_{1}\right)$.

Table 1 Fragment of information space with 10 information objects

\begin{tabular}{|c|c|c|c|c|c|c|c|}
\hline- & P1 & P2 & P3 & P4 & P5 & P6 & P7 \\
\hline IO1 & $2 \pm 0.2$ & NONE & $3 \pm 0.3$ & $7 \pm 0.5$ & $5 \pm 0.1$ & $10 \pm 0.9$ & $9 \pm 0.9$ \\
\hline IO2 & $2 \pm 0.9$ & $4 \pm 0.4$ & $7 \pm 0.4$ & $5 \pm 0.9$ & NONE & $9 \pm 0.2$ & $10 \pm 0.8$ \\
\hline IO3 & $3 \pm 0.3$ & $6 \pm 0.4$ & NONE & $8 \pm 0.7$ & $9 \pm 0.5$ & $7 \pm 0.9$ & $10 \pm 0.1$ \\
\hline IO4 & $1 \pm 0.9$ & $4 \pm 0.8$ & $7 \pm 0.6$ & $8 \pm 0.1$ & $6 \pm 0.5$ & $6 \pm 0.6$ & $8 \pm 0.4$ \\
\hline IO5 & $4 \pm 0.3$ & NONE & $6 \pm 0.5$ & $5 \pm 0.5$ & $9 \pm 0.7$ & $7 \pm 0.7$ & $9 \pm 0.8$ \\
\hline IO6 & $2 \pm 0.6$ & $5 \pm 0.1$ & $5 \pm 0.3$ & $7 \pm 0.7$ & $5 \pm 0.7$ & $10 \pm 0.7$ & NONE \\
\hline IO7 & NONE & NONE & $6 \pm 0.2$ & $4 \pm 0.1$ & $6 \pm 0.8$ & $7 \pm 0.9$ & $10 \pm 0.4$ \\
\hline IO8 & $3 \pm 0.9$ & $3 \pm 0.3$ & $5 \pm 0.4$ & $5 \pm 0.4$ & $7 \pm 0.9$ & $7 \pm 0.7$ & NONE \\
\hline IO9 & $5 \pm 0.7$ & $2 \pm 0.5$ & $6 \pm 0.3$ & $7 \pm 0.4$ & $8 \pm 0.2$ & $6 \pm 0.4$ & $9 \pm 0.4$ \\
\hline IO10 & $4 \pm 0.4$ & $2 \pm 0.6$ & $7 \pm 0.3$ & $4 \pm 0.8$ & $5 \pm 0.3$ & NONE & $11 \pm 0.5$ \\
\hline
\end{tabular}

In this case, the length of the interval for each parameter was 7 units, for example, for the parameter $P 1[1 ; 7]$.

The generalization of the results from our experiments has made it possible to draw a conclusion about the time of construction of an intermediate unified information space depending on the length of the interval Table 2.

Then, all information objects from each information space are combined into one intermediate unified information space. This is followed by the process of excluding repetitive information objects, that is, the intermediate single information space $U I S_{\text {int }}$ itself is rebuilt. The time of this operation, for example, in a variant when the intermediate unified information space contains 7 parameters and the length of the interval is 7 units, was 53.7 minutes. At the same time, of the initial 100,000, 96,376 unique information objects remained in the intermediate unified information space.
Table 2

The time to build an intermediate unified information space depending on the length of the interval of the parameters of information objects

\begin{tabular}{|c|c|c|c|c|c|}
\hline \multirow{2}{*}{$\begin{array}{c}\text { The number } \\
\text { of parame- }\end{array}$} & \multicolumn{5}{|c|}{ Time to build an intermediate unified information space, min. } \\
\cline { 2 - 6 } ters, unit & 3 & 4 & 5 & 6 & 7 \\
\hline 6 & 0.8 & 1.5 & 13.6 & 25.1 & 29.6 \\
\hline 7 & 4.3 & 20.1 & 25.6 & 30.2 & 53.7 \\
\hline 8 & 11.7 & 41.9 & 33.9 & 38.8 & 61.2 \\
\hline 9 & 29.3 & 59.9 & 46 & 54.5 & 72.2 \\
\hline 10 & 46.5 & 66.2 & 51.6 & 59.2 & 77.5 \\
\hline
\end{tabular}

The result was the following variants of the results:

1. When sensors read all the parameters of the incoming object and there was an unambiguous identification of it:

New object:

$2 \pm 0,86 \pm 0,64 \pm 0,48 \pm 0,67 \pm 0,17 \pm 0,18 \pm 0,8$.

Search object:

IO58852 $2 \pm 0,46 \pm 0,44 \pm 0,68 \pm 0,27 \pm 0,27 \pm 0,88 \pm 0,3$.

2. When sensors read all the parameters' values of an incoming object and did not identify it, there was no information object within the unified information space to describe this incoming object:

New object:

$5 \pm 0,23 \pm 0,27 \pm 0 \quad 5 \pm 0,47 \pm 09 \pm 0,2 \quad 11 \pm 0,4$.

Object absent!

3. When sensors read not all the values of all the parameters for an incoming object (there are $N U L L$-values) but there was an unambiguous identification of an incoming object in the intermediate unified information space:

New object:

Null $5 \pm 0.95 \pm 0.74 \pm 0.56 \pm 0.210 \pm 0.48 \pm 0.6$.

Search object:

IO15251 $2 \pm 0.15 \pm 0.85 \pm 0.14 \pm 0.56 \pm 0.110 \pm 0.18 \pm 0.4$

IO22474 $3 \pm 0.15 \pm 0.45 \pm 0.44 \pm 0.46 \pm 010 \pm 0.48 \pm 0.3$.

IO34227 $5 \pm 0.15 \pm 0.45 \pm 0.44 \pm 06 \pm 0.210 \pm 0.48 \pm 0.2$.

IO49215 $4 \pm 05 \pm 0.35 \pm 0.34 \pm 0.36 \pm 0.210 \pm 0.48 \pm 0.4$.

ReCreateObject:

$2 \pm 0.45 \pm 0.95 \pm 0.74 \pm 0.56 \pm 0.210 \pm 0.48 \pm 0.6$.

Search object:

IO15251 $2 \pm 0.15 \pm 0.85 \pm 0.14 \pm 0.56 \pm 0.110 \pm 0.18 \pm 0.4$.

4. When sensors read not all the values of all the parameters of an incoming object and the identification of an incoming object in the intermediate unified information space did not occur:

New object:

$4 \pm 0.3$ Null Null $8 \pm 0.312 \pm 0.16 \pm 0.614 \pm 0.2$.

Search object:

IO5301 $4 \pm 0.47 \pm 0.66 \pm 0.98 \pm 0.612 \pm 0.86 \pm 0.414 \pm 0.1$. IO6043 $4 \pm 0.12 \pm 0.66 \pm 0.28 \pm 0.112 \pm 0.66 \pm 0.314 \pm 0.1$. IO64393 $4 \pm 0.36 \pm 0.67 \pm 0.18 \pm 0.112 \pm 0.56 \pm 0.714 \pm 0.4$. ReCreateObject:

$4 \pm 0.34 \pm 0.1 \mathrm{Null} 8 \pm 0.312 \pm 0.16 \pm 0.614 \pm 0.2$.

ReCreateObject:

$4 \pm 0.34 \pm 0.18 \pm 0.98 \pm 0.312 \pm 0.16 \pm 0.614 \pm 0.2$.

Object absent! 
The generalized results of our experiments led to the conclusion that the search for incoming objects in the intermediate unified information space at 7 parameters and the length of the interval of 7 units is efficient Table 3.

Table 3

The efficiency of finding incoming objects in an intermediate unified information space at 7 parameters and a 7 -unit interval length

\begin{tabular}{|c|c|}
\hline $\begin{array}{c}\text { The probability that the } \\
\text { parameter is not read by } \\
\text { sensors }(\text { NULL }), \%\end{array}$ & $\begin{array}{c}\text { Probability of identifying an } \\
\text { incoming object, } \%\end{array}$ \\
\hline 5 & 7 \\
\hline 10 & 10 \\
\hline 15 & 7 \\
\hline 20 & 8 \\
\hline 25 & 7 \\
\hline
\end{tabular}

Table 3 demonstrates that the efficiency of finding incoming objects in an intermediate unified information space at 7 parameters and a 7 -unit interval is low. Therefore, it was decided to reduce the number of parameters that describe the object and, with the same raw data, to conduct similar experiments with the number of parameters from 4 to 6 . The results of our experiments are given in Table 4.

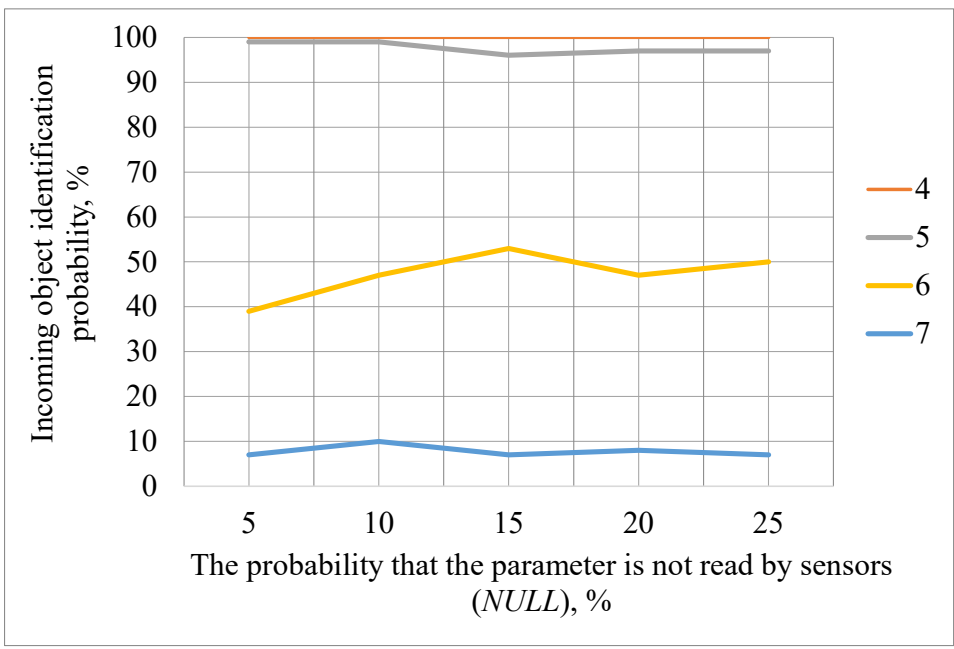

Fig. 3. A chart comparing the effectiveness of finding incoming objects in an intermediate unified information space at the interval length of 7 units and the number of parameters from 4 to 7

Table 4

The efficiency of finding incoming objects in an intermediate unified information space at 4-7 parameters and a 7-unit interval length

\begin{tabular}{|c|c|c|c|}
\hline \multirow{3}{*}{\begin{tabular}{|} 
The probability that the \\
parameter is not read by sensors \\
$($ NULL), \%
\end{tabular}} & \multicolumn{3}{|c|}{$\begin{array}{c}\text { Probability of identifying an } \\
\text { incoming object, } \%\end{array}$} \\
\hline & \multicolumn{3}{|c|}{ The number of parameters, units } \\
\hline & 4 & 5 & 6 \\
\hline 5 & 100 & 99 & 39 \\
\hline 10 & 100 & 99 & 47 \\
\hline 15 & 100 & 96 & 53 \\
\hline 20 & 100 & 97 & 47 \\
\hline 25 & 100 & 97 & 50 \\
\hline
\end{tabular}

Table 4 demonstrates that the probability of identifying an incoming object in an intermediate unified information space at 4 parameters and the length of the interval of 7 units is $100 \%$, that is, further reducing the number of parameters makes no sense. The time during which 100 experiments were conducted at the length of the interval of 7 units and the number of parameters from 4 to 7 , is given in Table 5 .

Table 5

The time during which 100 experiments were conducted at the interval length of 7 units and the number of parameters from 4 to 7

\begin{tabular}{|c|c|c|c|c|c|}
\hline \multirow{2}{*}{$\begin{array}{c}\text { The number of } \\
\text { parameters, unit }\end{array}$} & \multicolumn{5}{|c|}{ Time, s } \\
\cline { 2 - 6 } & \multicolumn{5}{|c|}{ The probability that the parameter is not read } \\
& 5 & 10 & 15 & 20 & 25 \\
\hline 4 & 6.1 & 5.1 & 6.9 & 9.5 & 9.1 \\
\hline 5 & 7.7 & 9.8 & 11.6 & 13.1 & 17.5 \\
\hline 6 & 13.6 & 13 & 13.1 & 12.7 & 13.2 \\
\hline 7 & 15.2 & 16.3 & 16.2 & 16.4 & 15.8 \\
\hline
\end{tabular}

Based on the data in Tables 3, 4, a chart was built to compare the effectiveness of finding incoming objects in an intermediate unified information space at the interval length of 7 units and the number of parameters from 4 to 7 .

\section{7 units and the number of parameters from 4 to 7}

Fig. 3 allows us to conclude that the efficiency of finding incoming objects in an intermediate unified information space at the interval length of 7 units was on average:

- at 4 parameters - $100 \%$;

- at 5 parameters $-97.6 \%$;

- at 6 parameters $-47.2 \%$;

- at 7 parameters $-7.8 \%$.

Based on the data in Table 5, we built a chart comparing the time of the search for incoming objects in an intermediate unified information space at the interval length of 7 units and the number of parameters from 4 to 7 (Fig. 4).

Fig. 4 allows us to conclude that the time to search for incoming objects in an intermediate unified information space at the interval length of 7 units was on average:

- at 4 parameters $-7.34 \mathrm{~s}$;

- at 5 parameters $-11.94 \mathrm{~s}$;

- at 6 parameters $-13.12 \mathrm{~s}$;

- at 7 parameters $-16.98 \mathrm{~s}$.

It follows from the above that the reduction in the number of parameters leads to a sharp increase in the efficiency of finding incoming objects in the intermediate unified information space.

Experiment 2. In analyzing the conclusions made after experiment 1, it was decided to increase the length of the interval of the parameters for incoming objects in the intermediate unified information space to 8 units.

Consider the case where each of the 20,000 information objects is described by the number of parameters from 4 to 7 at the interval length of 8 units. The results of our experiments are given in Table 6 .

Based on the data in Table 6, we built a chart to compare the effectiveness of finding incoming objects in an intermediate unified information space at the interval length of 8 units and the number of parameters from 4 to 7 (Fig. 5). 
Table 6

The effectiveness of finding incoming objects in an intermediate unified information space at the interval length of 8 units and the number of parameters from 4 to 7

\begin{tabular}{|c|c|c|c|c|c|}
\hline \multirow{3}{*}{$\begin{array}{c}\text { The number } \\
\text { of parame- } \\
\text { ters, unit }\end{array}$} & \multicolumn{5}{|c|}{ Probability of identifying an incoming object, \% } \\
\hline & \multicolumn{5}{|c|}{$\begin{array}{l}\text { The probability that the parameter is not read by } \\
\text { sensors }(N U L L), \%\end{array}$} \\
\hline & 5 & 10 & 15 & 20 & 25 \\
\hline 4 & 100 & 100 & 100 & 100 & 100 \\
\hline 5 & 91 & 84 & 91 & 94 & 90 \\
\hline 6 & 16 & 26 & 22 & 23 & 20 \\
\hline 7 & 3 & 4 & 2 & 5 & 1 \\
\hline
\end{tabular}

Fig. 5 allows us to conclude that the efficiency of finding incoming objects in an intermediate unified information space at the interval length of 8 units was on average:

- at 4 parameters - $100 \%$;

- at 5 parameters - $90 \%$;

- at 6 parameters $-21.4 \%$;

- at 7 parameters $-3.0 \%$.

It follows that increasing the length of the interval leads to a decrease in the efficiency of finding incoming objects in the intermediate unified information space.

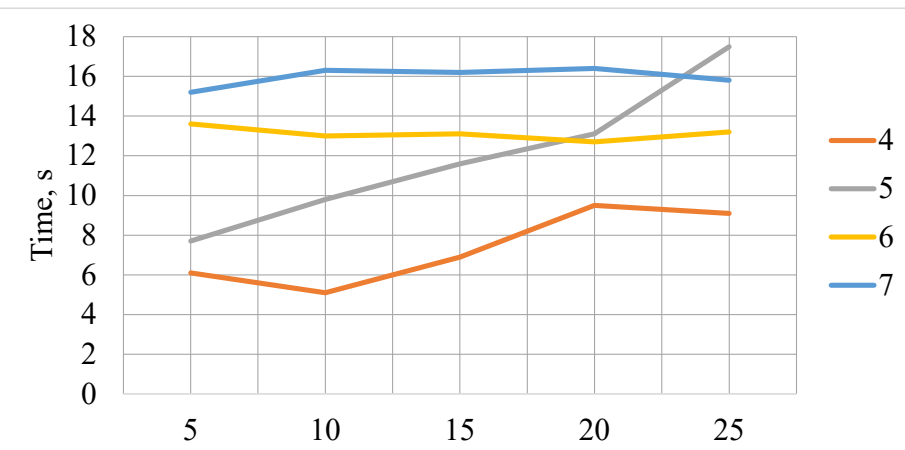

The probability that the parameter is not read by sensors (NULL), \%

Fig. 4. A chart comparing the time of the search for incoming objects in an intermediate unified information space at the interval length of 7 units and the number of parameters from 4 to 7

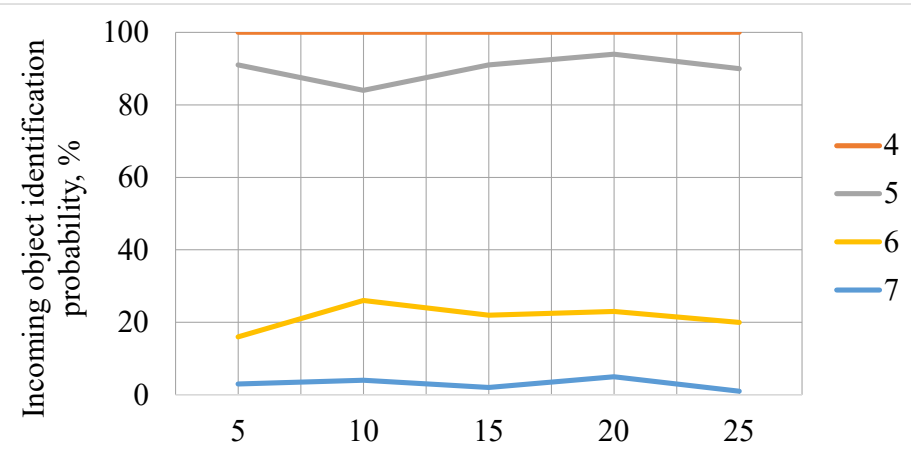

The probability that the parameter is not read by sensors $(N U L L), \%$

Fig. 5. A chart comparing the effectiveness of finding incoming objects in an intermediate unified information space at the interval length of 8 units and the number of parameters from 4 to 7
Experiment 3. Based on an analysis of the conclusions made after experiment 2 , it was decided to conduct similar experiments at smaller intervals of information object parameters.

Consider the case where each of the 20,000 information objects is described by 7 parameters at the interval length of 3 to 7 units. The results of our experiments are given in Table 7.

Table 7

The efficiency of finding incoming objects in an intermediate unified information space at 7 parameters and at the interval length from 3 to 7

\begin{tabular}{|c|c|c|c|c|c|}
\hline \multirow{2}{*}{$\begin{array}{l}\text { The interval } \\
\text { length, unit }\end{array}$} & \multicolumn{5}{|c|}{ Probability of identifying an incoming object, \% } \\
\cline { 2 - 6 } & 5 & 10 & 15 & 20 & 25 \\
\cline { 2 - 6 } sensors (NULL), \% \\
\hline 3 & 100 & 100 & 100 & 100 & 100 \\
\hline 4 & 98 & 97 & 96 & 96 & 95 \\
\hline 5 & 59 & 60 & 55 & 62 & 58 \\
\hline 6 & 24 & 28 & 21 & 24 & 20 \\
\hline 7 & 7 & 10 & 7 & 8 & 7 \\
\hline
\end{tabular}

Based on the data in Table 7 , we built a chart to compare the effectiveness of finding incoming objects in an intermediate unified information space at 7 parameters and at the interval length from 3 to 7 units (Fig. 6).

Fig. 6 demonstrates that the efficiency of finding incoming objects in the intermediate unified information space at 7 parameters and at the interval length from 3 to 7 units was on average:

- at the interval length of 3 units - $100 \%$;

- at the interval length of 4 units $-96.4 \%$;

- at the interval length of 5 units- $58.8 \%$;

- at the interval length of 6 units $-23.4 \%$;

- at the interval length of 7 units $-7.8 \%$.

Summing up the results of our experiments, the average efficiency of finding incoming objects in the intermediate unified information space was considered. These data are given in Table 8 with 6 to 10 parameters and at the interval length of 3 to 8 units. The average time to search for incoming objects in an intermediate unified information space with the number of parameters $6-10$ and at the interval length of 3-8 units is given in Table 9 .

Table 8

The average efficiency of finding incoming objects in an intermediate unified information space with 6 to 10 parameters and at the interval length from 3 to 8 units

\begin{tabular}{|c|c|c|c|c|c|c|}
\hline \multirow{3}{*}{$\begin{array}{c}\text { The number } \\
\text { of parame- }\end{array}$} & \multicolumn{7}{|c|}{$\begin{array}{c}\text { The average probability of identifying an } \\
\text { incoming object, \% }\end{array}$} \\
\cline { 2 - 7 } ters, unit & \multicolumn{7}{|c|}{ Interval length, unit } \\
\cline { 2 - 7 } & 3 & 4 & 5 & 6 & 7 & 8 \\
\hline 6 & 100 & 99.8 & 97.2 & 74 & 44.6 & 21.4 \\
\hline 7 & 100 & 96.4 & 58.8 & 23.4 & 6.4 & 3 \\
\hline 8 & 99.2 & 59.8 & 15.2 & 3.2 & 1.2 & 0.2 \\
\hline 9 & 94 & 18.2 & 3.2 & 0.2 & 0 & 0.4 \\
\hline 10 & 58.2 & 5.4 & 0.8 & 0 & 0 & 0 \\
\hline
\end{tabular}




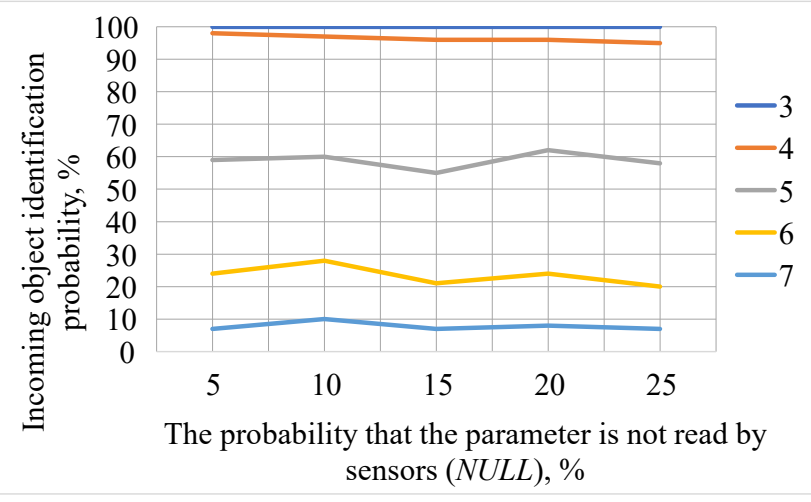

Fig. 6. A chart comparing the effectiveness of finding incoming objects in an intermediate unified information space at 7 parameters and at the interval length from 3 to 7 units

Table 9

Average time to search for incoming objects in an intermediate unified information space with the number of parameters from 6 to 10 and at the interval length from 3 to 8 units

\begin{tabular}{|c|c|c|c|c|c|c|}
\hline \multirow{2}{*}{$\begin{array}{c}\text { The number of } \\
\text { parameters, unit }\end{array}$} & \multicolumn{6}{|c|}{ Average time to identify an incoming object, s } \\
\cline { 2 - 7 } & 3 & 4 & 5 & 6 & 7 & 8 \\
\hline 6 & 8.64 & 9.8 & 13.34 & 16.3 & 23.54 & 19.34 \\
\hline 7 & 10.44 & 15.34 & 21.72 & 23.48 & 24.92 & 23.34 \\
\hline 8 & 14.86 & 24.46 & 27.58 & 25.82 & 27.54 & 27.24 \\
\hline 9 & 22.6 & 31.34 & 31.18 & 30.56 & 30.24 & 30.26 \\
\hline 10 & 34.22 & 33.96 & 32.14 & 33.96 & 31.84 & 35.02 \\
\hline
\end{tabular}

Based on the data in Table 8, we built a chart comparing the average efficiency of finding incoming objects in an intermediate unified information space. Fig. 7 shows such a chart with the number of parameters from 6 to 10 and at the interval length from 3 to 8 units.

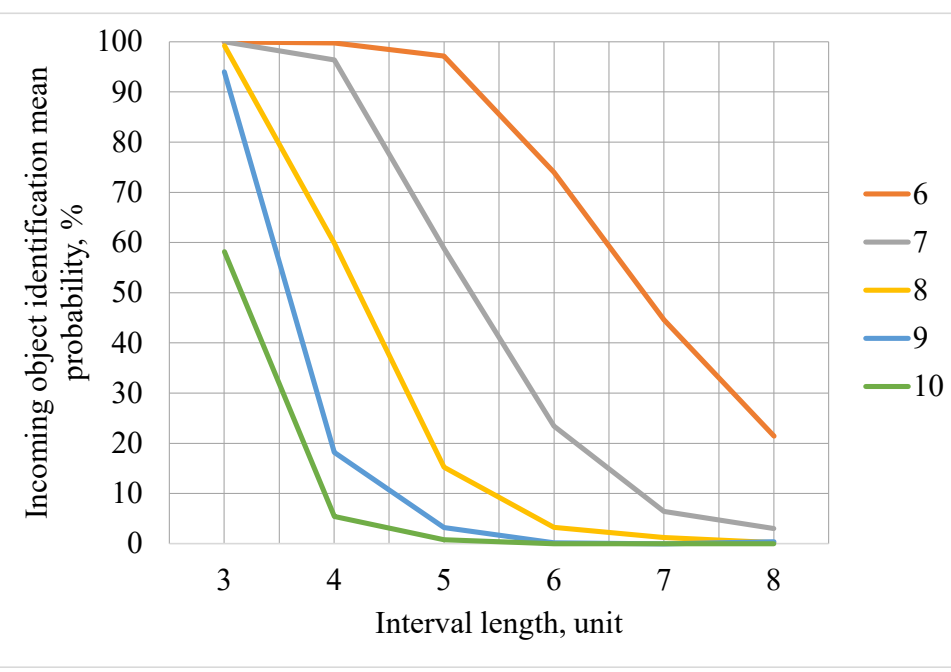

Fig. 7. A chart comparing the average efficiency of finding incoming objects in an intermediate unified information space with the number of parameters from 6 to 10 and the lengths of intervals from 3 to 8 units
Based on the data in Table 9, we built a chart comparing the average time of the search for incoming objects in the intermediate unified information space. Fig. 8 shows such a chart with the number of parameters from 6 to 10 and at the interval length from 3 to 8 units.

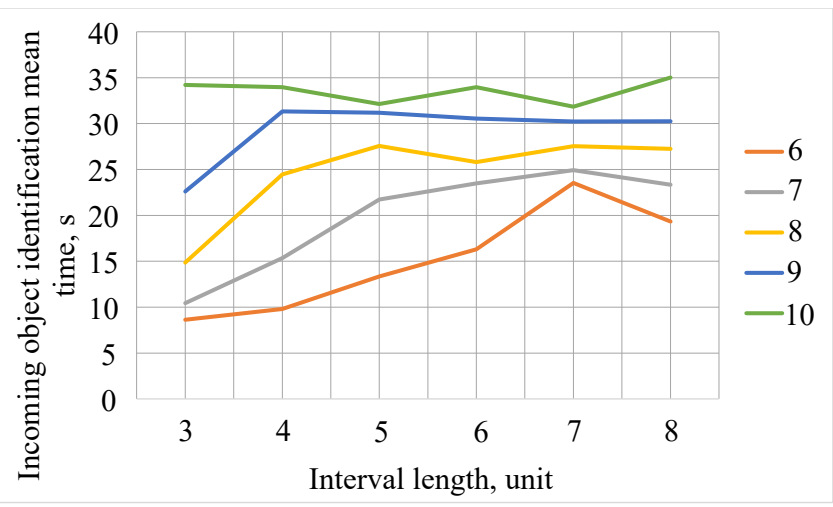

Fig. 8. A chart of the average time of searching for incoming objects in an intermediate unified information space with the number of parameters from 6 to 10 and the length of intervals from 3 to 8 units

The results of our experimental study show that the proposed method makes it possible to draw conclusions about the effectiveness and time of searching for incoming objects in the intermediate unified information space.

\section{Discussion of results regarding the method for identifying an incoming object based on the combination of information spaces}

The experimental study of the devised method was carried out to test the possibility of its use in the incoming object identification in a set of dynamically changing objects, as well as to establish its effectiveness relative to existing methods.

The considered comprehensive procedure of processing heterogeneous data [28] assesses the speed of processing information depending on the amount of information about the monitored object. Using the method that we have devised makes it possible to perform an assessment of the speed of identification of an object not only in the context of the amount of information about the object (the number of parameters) but also taking into consideration the degree of its heterogeneity (interval lengths). Thus, for the process of identifying objects, an expansion of the completeness of the criteria-based assessment of efficiency has been achieved.

The method of searching for information objects in the computer's memory employs the idea of superimposing the mask of an information object on the dataset, which is analogous to the information object dataset. This method also considers the option of incomplete matching between the parameters of the information object. A certain level of correlation is set in the interval from 0 to 1 (where 0 is a complete non-coincidence, $1-$ a complete match of the parameter value). After that, objects 
are searched by superimposing a mask with a bias on the input dataset. For each case, the correlation factor is assessed and the similarity of the information object and the subset of the original array is assessed based on this parameter. At the same time, in our method, the search is conducted based on a complete coincidence of parameters, that is, the correlation ratio is 1 . We also considered an option where some parameters of the information object may not be read by sensors (NULL), so they are subsequently restored.

It should be noted that the proposed method of identifying an incoming object based on the pooling of information spaces does not take into consideration the time cost of combining all information spaces into one intermediate unified information space. Therefore, this fact shows the obvious lack of the proposed method. The direction of further research related to its elimination should be focused on the development of the procedure for finding an incoming object in information spaces in parallel. That should minimize the time it takes to identify an incoming object.

\section{Conclusions}

1. We have proposed a mechanism for identifying incoming objects, which differs by combining information spaces into an intermediate unified information space, which makes it possible to improve the efficiency of identification of an incoming object at both local and global levels.

2. Based on the proposed method, the experiments were conducted that allow us to draw conclusions about the effectiveness and time of searching for incoming objects in information spaces. The efficiency of finding incoming objects in the intermediate unified information space was on average:

- at 6 parameters - $73.27 \%$; at 7 parameters - $48.23 \%$; at 8 parameters $-73.27 \%$; at 9 parameters $-18.8 \%$; at 10 parameters $-10.73 \%$;

- at the length of the interval of 3 units $-90.28 \%$; at the length of the interval of 4 units $-55.92 \%$; at the length of the interval of 5 units $-34.0 \%$; at the length of the interval of 6 units $-20.16 \%$; at the interval length of 7 units $11.12 \%$; and at the length of the interval of 8 units $-5.0 \%$.

It has been established that the efficiency of finding incoming objects in an intermediate unified information space tends to be a directly proportional dependence while reducing the length of the interval and increasing the number of parameters, and vice versa. At the same time, the time of the search for incoming objects in the intermediate unified information space was on average:

- at 6 parameters - $15.16 \mathrm{~s}$; at 7 parameters $-19.87 \mathrm{~s}$; at 8 parameters $-24.58 \mathrm{~s}$; at 9 parameters $-29.36 \mathrm{~s}$; at 10 parameters - $33.52 \mathrm{~s}$;

- at the length of the interval of 3 units $-18.15 \mathrm{~s}$; at the length of the interval of 4 units $-22.98 \mathrm{~s}$; at the length of the interval of 5 units $-25.19 \mathrm{~s}$; at the length of the interval of 6 units $-26.02 \mathrm{~s}$; at the length of the interval of 7 units $27.62 \mathrm{~s}$; and at the length of the interval of 8 units $-27.04 \mathrm{~s}$.

As a result, it was experimentally found that the more parameters that describe an information object, the less time to identify an object depends on the length of the interval.

\section{References}

1. Little, R.J., Rubin, D. B. (2019).Statistical analysis with missing data.John Wiley \& Sons. doi:https://doi.org/10.1002/9781119482260

2. Zhu, L., Shi, C., Guo, J. (2015). Mapping discovery modeling and its empirical research for the scientific and technological knowledge concept in unified concept space. Cluster Computing, 18 (1), 103-112. doi: https://doi.org/10.1007/s10586-013-0339-7

3. Teraoka, T. (2012). Organization and exploration of heterogeneous personal data collected in daily life. Human-Centric Computing and Information Sciences, 2 (1), 1. doi: https://doi.org/10.1186/2192-1962-2-1

4. Cheng, T., Lauw, H. W., Paparizos, S. (2012). Entity Synonyms for Structured Web Search. IEEE Transactions on Knowledge and Data Engineering, 24 (10), 1862-1875. doi: https://doi.org/10.1109/tkde.2011.168

5. Yalova, K., Zavgorodnii, V., Romanyukha, M., Sorokina, L. (2016). Challenges and prospects in development of e-learning system for IT students. International Journal of Continuing Engineering Education and Life-Long Learning, 26 (1), 25. doi: https:// doi.org/10.1504/ijceell.2016.075042

6. Shevchenko, I., Tertyshnyi, V., Koval, S. (2017). Designing a model of a decision support system based on a multi-aspect factographic search. Eastern-European Journal of Enterprise Technologies, 4 (2 (88)), 20-26. doi: https://doi.org/10.15587/ 1729-4061.2017.108569

7. Jáñez Morán, A., Profaizer, P., Herrando Zapater, M., Andérez Valdavida, M., Zabalza Bribián, I. (2016). Information and Communications Technologies (ICTs) for energy efficiency in buildings: Review and analysis of results from EU pilot projects. Energy and Buildings, 127, 128-137. doi: https://doi.org/10.1016/j.enbuild.2016.05.064

8. Yakovis, L. M. (2016). From unified information space to unified manufacturing control. Automation and Remote Control, 77 (9), 1689-1698. doi: https://doi.org/10.1134/s0005117916090150

9. Hu, Z., Mukhin, V., Kornaga, Y., Herasymenko, O., Mostoviy, Y. (2018). The Analytical Model for Distributed Computer System Parameters Control Based on Multi-factoring Estimations. Journal of Network and Systems Management, 27 (2), 351-365. doi: https://doi.org/10.1007/s10922-018-9468-x

10. Mukhin, V., Volokyta, A., Heriatovych, Y., Rehida, P. (2018). Method for Efficiency Increasing of Distributed Classification of the Images based on the Proactive Parallel Computing Approach. Advances in Electrical and Computer Engineering, 18 (2), 117-122. doi: https://doi.org/10.4316/aece.2018.02015

11. Teslia, I., Yehorchenkova, N., Khlevna, I., Kataieva, Y., Latysheva, T., Yehorchenkov, O. et. al. (2020). Developing a systems engineering concept for digitalizing higher education institutions. Eastern-European Journal of Enterprise Technologies, 6 (2 (108)), 6-20. doi: https://doi.org/10.15587/1729-4061.2020.219260 
12. Biloshchytskyi, A., Kuchansky, A., Andrashko, Y., Biloshchytska, S., Kuzka, O., Shabala, Y., Lyashchenko, T. (2017). A method for the identification of scientists' research areas based on a cluster analysis of scientific publications. Eastern-European Journal of Enterprise Technologies, 5 (2 (89)), 4-11. doi: https://doi.org/10.15587/1729-4061.2017.112323

13. El Kadiri, S., Grabot, B., Thoben, K.-D., Hribernik, K., Emmanouilidis, C., von Cieminski, G., Kiritsis, D. (2016). Current trends on ICT technologies for enterprise information systems. Computers in Industry, 79, 14-33. doi: https://doi.org/10.1016/ j.compind.2015.06.008

14. Arenas, M., Cuenca Grau, B., Kharlamov, E., Marciuška, Š., Zheleznyakov, D. (2016). Faceted search over RDF-based knowledge graphs. Journal of Web Semantics, 37-38, 55-74. doi: https://doi.org/10.1016/j.websem.2015.12.002

15. Arenas, M., Grau, B. C., Kharlamov, E., Marciuska, S., Zheleznyakov, D. (2014). Enabling Faceted Search over OWL 2 with SemFacet. OWLED, 121-132. Available at: https://citeseerx.ist.psu.edu/viewdoc/download?doi=10.1.1.660.9713\&rep=rep1\&type=pdf

16. Nagpal, G., Uddin, M., Kaur, A. (2012). A Comparative Study of Estimation by Analogy using Data Mining Techniques. Journal of Information Processing Systems, 8 (4), 621-652. doi: https://doi.org/10.3745/jips.2012.8.4.621

17. Mukhin, V., Komaga, Y., Zavgorodnii, V., Zavgorodnya, A., Herasymenko, O., Mukhin, O. (2019). Social Risk Assessment Mechanism Based on the Neural Networks. 2019 IEEE International Conference on Advanced Trends in Information Theory (ATIT). doi: https:// doi.org/10.1109/atit49449.2019.9030519

18. Wang, T., Liu, L., Liu, N., Zhang, H., Zhang, L., Feng, S. (2020). A multi-label text classification method via dynamic semantic representation model and deep neural network. Applied Intelligence, 50 (8), 2339-2351. doi: https://doi.org/10.1007/s10489-020-01680-w

19. Pan, Y., Hu, G., Qiu, J., Zhang, Y., Wang, S., Shao, D., Pan, Z. (2020). FLGAI: a unified network embedding framework integrating multi-scale network structures and node attribute information. Applied Intelligence, 50 (11), 3976-3989. doi: https:// doi.org/10.1007/s10489-020-01780-7

20. Yu, W., Cheng, S., Wu, C., Lou, H. (2012). A self-evolutionary model for automated innovation of construction technologies. Automation in Construction, 27, 78-88. doi: https://doi.org/10.1016/j.autcon.2012.04.018

21. Grau, B. C., Kharlamov, E., Marciuska, S., Zheleznyakov, D., Arenas, M. (2016). SemFacet: Faceted Search over Ontology Enhanced Knowledge Graphs. International Semantic Web Conference. Available at: http://citeseerx.ist.psu.edu/viewdoc/download?doi=10. 1.1.1068.337\&rep=rep1\&type=pdf

22. Ferré, S., Hermann, A. (2011). Semantic Search: Reconciling Expressive Querying and Exploratory Search. Lecture Notes in Computer Science, 177-192. doi: https://doi.org/10.1007/978-3-642-25073-6_12

23. Dodonov, A., Mukhin, V., Zavgorodnii, V., Kornaga, Ya., Zavgorodnya A. (2021). Method of searching for information objects in unified information space. System research and information technologies, 1, 34-46. doi: https://doi.org/10.20535/ SRIT.2308-8893.2021.1.03

24. Ferré, S., Hermann, A., Ducassé, M. (2011). Semantic faceted search: Safe and expressive navigation in RDF graphs. HAL. Available at: https://hal.inria.fr/inria-00554093/document

25. Gershkovich, M. M., Birukova, T. K. (2014). The tasks of identification of informational objects in area-spread data arrays. Systems and Means of Informatics, 24 (1), 224-243. doi: https://doi.org/10.14357/08696527140114

26. Ozhereleva, T. A. (2014). Regard to the concept of information space, information field, information environment and semantic environment. International Journal of Applied and Fundamental Research, 10-2, 21-24. Available at: https://applied-research.ru/ $\mathrm{ru} / \mathrm{article} / \mathrm{view}$ ?id $=5989$

27. Karin, S. A. (2012). Integration in the Single Information Space of Heterogeneous Geospatial Data. Information and Control Systems, 2 (57), 89-94. Available at: http://www.i-us.ru/index.php/ius/article/view/13797

28. Zuiev, P., Zhyvotovskyi, R., Zvieriev, O., Hatsenko, S., Kuprii, V., Nakonechnyi, O. et. al. (2020). Development of complex methodology of processing heterogeneous data in intelligent decision support systems. Eastern-European Journal of Enterprise Technologies, 4 (9 (106)), 14-23. doi: https://doi.org/10.15587/1729-4061.2020.208554

29. Logunov, A. N., Logunova, G. L. (2012). Choice of recognition attributes when searching hidden objects. Eastern-European Journal of Enterprise Technologies, 5 (9 (59)), 21-25. Available at: http://journals.uran.ua/eejet/article/view/4622

30. Meshcheryakov, R. V., Zhukovskiy, O. I., Senchenko, P. V., Gritsenko, Y. B., Milikhin, M. M. (2017). Architecture features of a common information space to manage complex technological processes. Proceedings of Tomsk State University of Control Systems and Radioelectronics, 20 (4), 75-81. doi: https://doi.org/10.21293/1818-0442-2017-20-4-75-81

31. Manakova, I. P. (2016). Sistema integratsii kontenta iz oblachnyh hranilisch i sotsial'nyh setey v edinoe informatsionnoe prostranstvo organizatsii. Nauchno-metodicheskiy elektronniy zhurnal Kontsept, 15, 476-480. Available at: https://e-koncept.ru/ 2016/86999.htm

32. Mukhin, V., Zavgorodnii, V., Barabash, O., Mykolaichuk, R., Kornaga, Y. et. al. (2020). Method of Restoring Parameters of Information Objects in a Unified Information Space Based on Computer Networks. International Journal of Computer Network and Information Security, 12 (2), 11-21. doi: https://doi.org/10.5815/ijcnis.2020.02.02

33. Sheludko, A. A., Boldyrikhin, N. V. (2018). Search of information objects in computer memory solving the problems of cyber security provision. Molodoy issledovatel' Dona, 6 (15), 81-86. Available at: https://cyberleninka.ru/article/n/poisk-informatsionnyhobektov-v-pamyati-kompyutera-pri-reshenii-zadach-obespecheniya-kiberbezopasnosti 